\title{
Successful penile reconstruction following prior arteriovenous loop thrombosis due to undiagnosed protein-S deficiency and exogenous testosterone
}

\author{
Parameswaran Anoop, Vithal Malmande ${ }^{1}$, M. N. Prakash Kumar ${ }^{1}$, Naveen Rao ${ }^{1}$ \\ Departments of Hematology and ${ }^{1}$ Plastic Surgery, Apollo Hospitals, Bengaluru, Karnataka, India
}

Address for correspondence: Dr. Parameswaran Anoop, Apollo Hospitals, 154/11, Opposite IIM (B), Bannerghatta Road, Bengaluru - 560 076, Karnataka, India. E-mail: docanoop@yahoo.com

\section{ABSTRACT}

Flap failure from microvascular thrombotic occlusion is a rare but significant cause for unsuccessful reconstructive surgery. We encountered thrombosis of arteriovenous loop in a patient undergoing phallus reconstruction. Further investigations revealed underlying previously asymptomatic hypercoagulable state due to protein-S deficiency in addition to long-term exogenous testosterone administration. Role of thrombophilia testing, thrombogenic potential of testosterone and the need for therapeutic perioperative anti-coagulation in such situations are described here.

\section{KEY WORDS}

Microvascular thrombosis; testosterone; thrombophilia

\section{INTRODUCTION}

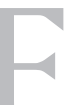
emale to male gender change requires multiple $\checkmark$ challenging surgical procedures, one of which is phallus reconstruction with free radial artery forearm flap (RAFF). Flap failure from microvascular thrombosis is estimated to occur in $5-10 \%$ of reconstructive procedures and after surgical technique, is the most significant prognostic factor. ${ }^{[1]}$ Inherited thrombophilia can often remain asymptomatic for years and then suddenly manifest in adulthood with a major thrombo-embolic episode in the presence of concurrent additional risk factors. Here, we report one such situation

\begin{tabular}{|l|l|}
\hline \multicolumn{2}{|c|}{ Access this article online } \\
\hline Quick Response Code: & Website: \\
\hline & www.ijps.org \\
\cline { 2 - 2 } & \\
\hline
\end{tabular}

of failure of arteriovenous (AV) loop due to thrombotic occlusion despite routine thromboprophylaxis.

\section{CASE REPORT}

A 30-year-old person with gender identity disorder, biologically female, was admitted for phallus reconstruction as part of sex change surgery. She had previously undergone mastectomy, hysterectomy and partial vaginectomy 3 years ago and had been receiving testosterone (Sustanon ${ }^{\circledR}$, Organon Pharmaceuticals, Oss, Netherlands) $100 \mathrm{mg}$ intramuscularly every 4 weeks

This is an open access article distributed under the terms of the Creative Commons Attribution-NonCommercial-ShareAlike 3.0 License, which allows others to remix, tweak, and build upon the work non-commercially, as long as the author is credited and the new creations are licensed under the identical terms.

For reprints contact: reprints@medknow.com

How to cite this article: Anoop P, Malmande V, Prakash Kumar MN, Rao N. Successful penile reconstruction following prior arteriovenous loop thrombosis due to undiagnosed protein-S deficiency and exogenous testosterone. Indian J Plast Surg 2016;49:268-70. 
since then. All previous surgical procedures were uncomplicated, and there was no antecedent medical history of bleeding or thrombotic episodes.

As the first stage, vaginectomy with urethral advancement, suprapubic catheterisation and AV access loop creation was performed. The left long saphenous vein was cut at lower thigh, looped across the perineum and was anastomosed end-to-side to the femoral artery. Postoperatively, thromboprophylaxis was started with enoxaparin $0.5 \mathrm{mg} / \mathrm{kg}$ subcutaneously 12-hourly with 2-hourly Doppler monitoring of AV loop. After $48 \mathrm{~h}$, the patient was taken up for the next stage, phallus reconstruction [Figure 1a] with free RAFF and clitoris excision. Arterial Doppler signals in the perineum close to the base of the future penis were found to be adequate. Following phallus creation with RAFF in the left forearm, the groin wound was explored for AV loop, which was found to be thrombosed at the end-to-side anastomotic site [Figure 1b]. A fresh AV loop to the same arteriotomy site was done with distal great saphenous vein graft harvested from the left leg. The graft was anastomosed between the femoral artery and the proximal stump of the great saphenous vein. Clitoris excision was done; the phallus was left in situ in the forearm and raw area was covered with split-thickness skin graft. Unfractionated heparin (UFH) was commenced postoperatively at a dose of 5000 units subcutaneously 8-hourly this time. Doppler monitoring was done at $2 \mathrm{~h}$ intervals. At $72 \mathrm{~h}$, signals were weak and hence re-exploration was done, which showed the AV loop to be still thrombosed and almost completely occluded. The loop was removed and femoral arteriotomy site was repaired with vein patch.

Haematologist's opinion was sought in view of this complication. Thrombophilic work-up revealed protein-S deficiency (free protein-S 8\%, range 60-140) and hyperhomocysteinemia (42 mmol/L, range $4-14)$. Normal

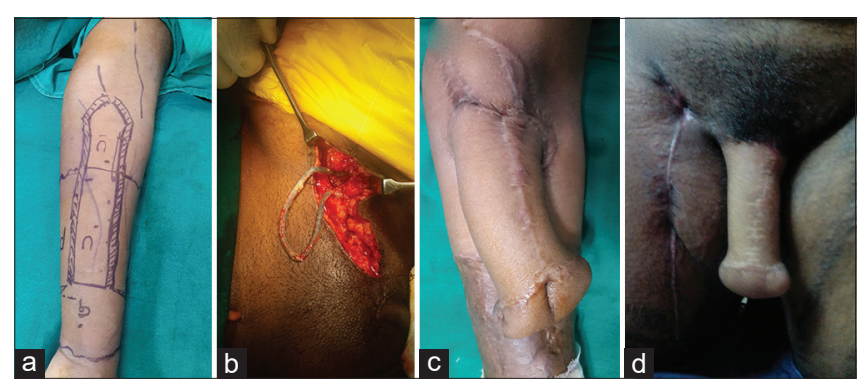

Figure 1: (a) Left forearm with the plan for phallus construction,

(b) thrombosed arteriovenous loop per-operatively, (c) phallus left in situ on the left forearm, (d) well vascularised phallus at 6 weeks of follow-up levels of protein- $\mathrm{C}$ and anti-thrombin were noted. Lupus anti-coagulant and anti-phospholipid antibodies were absent. Factor $\mathrm{V}$ Leiden, methylene tetrahydrofolate reductase and prothrombin gene mutations were not detected. UFH was continued for $72 \mathrm{~h}$ postoperatively and daily oral clopidrogel $75 \mathrm{mg}$ was commenced.

In conjunction with the haematologist, delayed transfer of phallus from forearm [Figure 1c] to the perineum was planned. After stopping testosterone for 3 months, patient was re-admitted and pre-operative anti-coagulation was commenced using intravenous UFH. Loading dose of 5000 units was followed by infusion of 18 units $/ \mathrm{kg} / \mathrm{h}$ with a target activated partial thromboplastin time (APTT) ratio of 1.5-2.5. Anti-platelet therapy was changed from clopidogrel to aspirin $75 \mathrm{mg}$ daily in view of the higher bleeding risk of the former. Adequate peri-operative intravenous hydration was provided. UFH was stopped $4 \mathrm{~h}$ prior to surgery and restarted immediately after arterial anastomosis. Reconstructed phallus was transferred from forearm to perineum. The radial artery was anastomosed end-to-side to right femoral artery with a long saphaneous vein graft from distal thigh. The proximal long saphenous vein from thigh was anastomosed to cephalic vein. Postoperatively, the UFH infusion and intravenous hydration were continued until $48 \mathrm{~h}$ with strict maintenance of APTT target ratio. Minimal groin wound bleeding was encountered on the $2^{\text {nd }}$ day with a drop of haemoglobin by $2.8 \mathrm{~g} / \mathrm{dl}$. Bleeding settled and UFH infusion were changed to enoxaparin $1 \mathrm{mg} / \mathrm{kg}$ subcutaneously twice daily. Concurrent warfarin was started and after achieving a therapeutic range international normalised ratio (2-3), enoxaparin was stopped. Doppler monitoring of the flap was done 2-hourly until $5^{\text {th }}$ post-operative day and blood flow was found to be adequate. Patient was discharged on aspirin and warfarin. At 6 weeks follow-up, the phallus was well vascularised [Figure $1 \mathrm{~d}$ ] and all wounds had healed with no further bleeding issues. A total of 12 weeks of warfarinisation was completed.

\section{DISCUSSION}

Inherited thrombophilic conditions have been described as rare causes of microvascular thrombosis resulting in flap failures. ${ }^{[2-4]}$ In addition, acquired thrombophilic states such as anti-phospholipid syndrome can also result in flap thrombosis. ${ }^{[5]}$ Drug-induced thrombosis can result from hormonal preparations, notably oestrogen. ${ }^{[6]}$ In 
contrast, testosterone was not a well-recognised cause for thrombosis until recent times. ${ }^{[-9]}$ Glueck and Wang had previously reported that exogenous testosterone administration in a subject with thrombophilia causes thrombosis within a median of 5 months. ${ }^{[10]}$ However, our patient with protein-S deficiency was on testosterone supplementation for a prolonged period of 3 years without any arterial or venous thrombotic episodes prior to the surgical challenge. We hypothesise that AV loop thrombosis could have been caused by the thrombophilic state (hyperhomocysteinemia and testosterone) with the added stress of microvascular surgery and pre-operative dehydration.

Thrombophilia work-up is an expensive and complex test to detect rare hypercoagulable states. Hence, it cannot be recommended as a routine screening test prior to reconstructive surgeries. However, following microvascular thrombosis as in our case and in patients who have additional risk factors such as testosterone supplementation, full thrombophilia testing should be done to ascertain the aetiology. Care must be taken to ensure adequate hydration and avoid the usage of concurrent drugs such as testosterone. Creation of a temporary $\mathrm{AV}$ shunt prior to microvascular tissue transfer is to be avoided. Close liaison with a haematologist is recommended in complex situations such as the one described here.

This case is reported as an approach to a situation with a failed AV loop and subsequent successful microvascular tissue transfer.

\section{Financial support and sponsorship}

Nil.

\section{Conflicts of interest}

There are no conflicts of interest.

\section{REFERENCES}

1. Ashjian P, Chen CM, Pusic A, Disa JJ, Cordeiro PG, Mehrara BJ. The effect of postoperative anticoagulation on microvascular thrombosis. Ann Plast Surg 2007;59:36-9.

2. Friedman $T$, O'Brien Coon $D$, Michaels $V \mathrm{~J}$, Bontempo $\mathrm{F}$, Young VL, Clavijo JA, et al. Hereditary coagulopathies: Practical diagnosis and management for the plastic surgeon. Plast Reconstr Surg 2010;125:1544-52.

3. Bowman KG, Carty MJ. Flap complications and thrombophilia: An evidence-based model and cost analysis for preoperative screening. Eplasty 2011;11:e32.

4. Handschin AE, Guggenheim M, Calcagni M, Künzi W, Giovanoli P. Factor V Leiden mutation and thrombotic occlusion of microsurgical anastomosis after free TRAM flap. Clin Appl Thromb Hemost 2010;16:199-203.

5. Salgarello M, Cervelli D, Barone-Adesi L. A massive arterial thrombosis of a free anterolateral thigh flap in a patient with antiphospholipid syndrome. Microsurgery 2008;28:447-51.

6. Tchaikovski SN, Rosing J. Mechanisms of estrogen-induced venous thromboembolism. Thromb Res 2010;126:5-11.

7. Freedman J, Glueck CJ, Prince M, Riaz R, Wang P. Testosterone, thrombophilia, thrombosis. Transl Res 2015;165:537-48.

8. Liljeqvist S, Helldén A, Bergman U, Söderberg M. Pulmonary embolism associated with the use of anabolic steroids. Eur $\mathrm{J}$ Intern Med 2008;19:214-5.

9. Glueck CJ, Goldenberg N, Budhani S, Lotner D, Abuchaibe C, Gowda M, et al. Thrombotic events after starting exogenous testosterone in men with previously undiagnosed familial thrombophilia. Transl Res 2011;158:225-34.

10. Glueck CJ, Wang P. Testosterone therapy, thrombosis, thrombophilia, cardiovascular events. Metabolism 2014;63:989-94. 